BIOMEDICAL AND BIOSOCIAL ANTHROPOLOGY
$\begin{gathered}\text { Official Journal of the International Academy } \\ \text { of Integrative Anthropology } \\ \text { journal homepage: http://bba-journal.com }\end{gathered}$

\title{
Dynamics of changes in the main indicators of reproductive health of women receiving chemotherapy for malignant breast tumors
}

\section{Shamrai V. A. ${ }^{1,2}$, Misiurko O. I.1,2, Grebeniuk D. I. ${ }^{1}$}

${ }^{1}$ National Pirogov Memorial Medical University, Vinnytsya, Ukraine

2Utility non-profit enterprise "Podillian Regional Oncology Center of Vinnitsa Regional Council", Vinnytsya, Ukraine

\section{ARTICLE INFO \\ Received: 05 March 2021 \\ Accepted: 07 April 2021}

UDC: $618.19+616-006.6+618.177$

\section{CORRESPONDING AUTHOR}

e-mail: doctor.svo@gmail.com Grebeniuk D. I.

\begin{abstract}
Breast cancer is the second most common cancer in the world and the most common cancer among women. The use of chemotherapy as a component of comprehensive treatment leads to the development of chemoinduced premature ovarian failure. The aim of the study was to examine the dynamics of changes in the main indicators of reproductive health of women who received chemotherapy for malignant neoplasms of the breast. Reproductive health of patients (levels of antimullerian hormone, estradiol and follicle-stimulating hormone, ovarian volume and number of antral follicles) before chemotherapy and one, two, and three years after completion of chemotherapy was studied according to the purpose and objectives of the study. The obtained data were processed using the statistical software package SPSS 20.0 for Windows. Quite significant changes in the reproductive health of women in the study group were manifested in the form of menstrual disorders (oligomenorrhea, amenorrhea), involuntary abortions, inability to conceive. Changes in hormonal status were characterized by a progressive decrease in antimullerian hormone and estradiol levels and an increase in follicle-stimulating hormone levels. In addition, there was a decrease in ovarian volume and a decrease in the number of antral follicles. The dynamics of changes in the studied indicators was characterized by a sharp deterioration during the first year after chemotherapy, followed by less rapid progression. This trend is explained by dystrophic changes in ovarian tissue after chemotherapy, and at a later date - in addition, the agerelated involution of the ovaries. The dynamics of changes in the main hormonal and ultrasound parameters of the ovarian reserve indicates significant impairment of reproductive function in women receiving chemotherapy for malignant neoplasms of the breast.

Keywords: breast cancer, chemotherapy, chemoinduced premature ovarian failure, female reproductive system.
\end{abstract}

\section{Introduction}

Breast cancer is the second most common cancer in the world and the most common cancer among women [24]. Even in developed countries, every eighth woman is at risk of developing this pathology [10].

The incidence of breast cancer varies in different parts of the world, ranging from 27 per 100,000 in Central Africa and East Asia to 92 per 100,000 in North America [16, 17]. For more developed regions, this figure is 74.1 , for less developed - 31.3 [40]. Almost a quarter of all cases of this pathology occur in the Asia-Pacific region, with the highest rates observed in China, Japan and Indonesia [14, 16, 17, 19, 44].

Given the current growth rate, the incidence of breast cancer could reach 3.2 million by 2050 [20].
Regarding the structure of breast cancer incidence, in the United States, for example, in 2017, approximately 252,710 new cases of invasive breast cancer and 6,341 cases of breast cancer were diagnosed in situ [10].

Due to the high availability of modern diagnostic and treatment procedures in the developed, the overall survival in this contingent is constantly increasing, and the 5-year survival rate reaches $89.0 \%$ [33]. One-year survival in Europe ranges from $94.1 \%$ in Scotland to $97.1 \%$ in Italy [42]. At the same time, the survival rate among African women is much lower [1].

In terms of breast cancer mortality, the anti-record for developing countries was set in 2012, when the pathology ranked fifth in the structure of cancer mortality out of 324,000 
deaths. At the same time, in developed countries this figure was second only to lung cancer mortality and amounted to 197,000 or $15.4 \%$ of all deaths in oncology [14]. Although the prevalence of breast cancer is higher in developed countries, higher mortality rates are observed in less developed regions [15].

Due to the high level of medicine in the United States in $2017,89.0 \%$ of deaths from breast cancer occurred in women aged 50 years and older [7, 10]. Mortality rates range from 6 cases per 100,000 people in East Asia to 20 cases per 100,000 people in West Africa [24]. For more developed regions, this figure is 14.9 , for less developed $11.5[21,40]$.

However, in addition to high morbidity and mortality, there is a problem of a slightly different plan - ovarian toxicity of chemotherapeutic agents and the associated chemoinduced premature ovarian failure [27, 39].

Chemotherapy, as part of a comprehensive treatment for breast cancer, is indicated for the vast majority of women with breast cancer. Adjuvant chemotherapy is indicated for most patients with tumors from stage I and larger than 1 $\mathrm{cm}[11,18,32]$. If in the early stages of breast cancer chemotherapy allows to achieve complete remission of the disease, then in metastatic cancer its role is to prolong life expectancy and improve its quality [6].

Along with the good results of various chemotherapy regimens, this method of treatment, due to the high overall toxic effect on the body, has a large number of adverse reactions [30, 36].

As for the toxic effect on ovarian tissue, it is carried out mainly due to damage to primary oocytes, granulosa cells and ovarian stroma. Chemotherapy has also been shown to cause significant vascular damage, including thickening and proliferation of cortical vessels, focal cortical fibrosis, and segmental collagen deposition [3, 23].

Ultimately, the toxic effects of chemotherapeutic agents on the ovaries lead to the loss of their function and the development of a number of related pathological conditions, including infertility [5, 41].

The aim of the study was to examine the dynamics of changes in the main indicators of reproductive health of women who received chemotherapy for malignant neoplasms of the breast.

\section{Materials and methods}

Prospective study was conducted at the Department of Obstetrics and Gynecology № 1 National Pirogov Memorial Medical University, Vinnytsya on the basis of the Podillia regional center of oncology.

The study was conducted with the permission of the Committee on Bioethics of National Pirogov Memorial Medical University, Vinnytsya and did not contradict the basic bioethical norms of the Declaration of Helsinki adopted by the General Assembly of the World Medical Association, the Council of Europe Convention on Human Rights and Biomedicine (1977), the relevant provisions of the WHO, the International Council of Medical Societies, the International Code of Medical Ethics (1983).

During 2015-2017, we analyzed the data of 2173 patients with malignant neoplasms of the breast.

According to the $\mathrm{WHO}$ classification, the reproductive age of women is 15-49 years.

In the study continent, the total number of women of reproductive age was $536(24.7 \%)$. Of these, $433(19.9 \%$ of the total) women received chemotherapy as a component of comprehensive treatment for breast cancer.

Age 40-45 years is a period of menopausal transition, when there is a natural decline in ovarian function. Given this fact, as well as the fact that in accordance with the purpose and objectives of the study, the planned observation was to last 3 years, for further study it was decided to create a sample of patients aged 15-36 years.

During the study period, 75 patients were selected (23 in 2015, 21 in 2016 and 31 in 2017), meeting the above criteria. However, women with both hormone-dependent and hormone-independent breast cancer were present in this sample.

In hormone-dependent breast cancer, hormone suppression is often used, which dramatically changes the hormonal background of patients. Therefore, we decided to study the target group of women with hormoneindependent breast cancer. There were 32 such women in the study contingent (13 in 2015, 12 in 2016 and 7 in 2017) and they were included in the main group.

According to the purpose and objectives of the study, the reproductive health of patients before chemotherapy, as well as one, two and three years after completion of chemotherapy was studied.

The development and nature of menstrual disorders, planning and course of pregnancy were studied. In addition, the morphofunctional state of the ovaries was studied. For this purpose, the levels of antimullerian hormone $(A M H)$, estradiol (E2) and follicle-stimulating hormone (FSH) were determined by enzyme-linked immunosorbent assay using the kits Human anti-Mullerian hormone (AMH) ELISA kit (CSB-E12756h), Human Estradiol,E2 ELISA Kit (CSBE05108h) and Human follicle-stimulating hormone, FSH ELISA Kit (CSB-E06867h) manufactured by CUSABIO (China).

Levels of antimullerian and follicle-stimulating hormones were determined for 3-5 days of the menstrual cycle, estradiol - for 5-7 days of the menstrual cycle.

Ultrasound examination of the ovaries was performed for 2-3 days of the menstrual cycle on the device of Toshiba (Japan). The volume of the ovaries and the number of antral follicles were determined.

To determine the reference values of the studied indicators, similar studies were performed once on relatively healthy women of reproductive age, who formed a control group $(\mathrm{n}=32)$.

The obtained data were processed using the statistical software package SPSS 20.0 for Windows. 


\section{Results}

The structure of the incidence of malignant neoplasms of the breast in the study sample of patients in accordance with ICD-10 is shown in table 1.

The most frequent localization of malignant neoplasms of the breast in the studied continent was localization in the upper outer quadrant $(40.63 \%)$. Localization in the lowerouter quadrant was observed somewhat less frequently $(25.00 \%)$. The study sample did not present unspecified localizations, localizations in the area of the nipple and areola, axillary posterior part of the breast, as well as lobular in situ carcinoma of the breast and intraductal carcinoma in situ of the breast.

Regarding the distribution of malignant neoplasms depending on the stage of the cancer process, it was as follows (Fig. 1).

The vast majority of malignant neoplasms were diagnosed in stages $2 \mathrm{~A}(40.60 \%)$ and $2 \mathrm{~B}(37.50 \%)$. Stages $1,3 \mathrm{~A}, 3 \mathrm{~B}$ and $3 \mathrm{C}$ were represented by isolated cases. There were no patients with stage 0 or 4 breast cancer in

Table 1. The structure of the incidence of malignant neoplasms of the breast in the studied contingent in accordance with ICD-10.

\begin{tabular}{|l|c|}
\hline \multicolumn{1}{|c|}{ Diagnosis } & $\begin{array}{c}\text { Number of } \\
\text { patients }\end{array}$ \\
\hline $\mathrm{MN}$ of nipple and areola (C50.00) & - \\
\hline $\mathrm{MN}$ of the central part of the breast (C50.10) & $4(12.50 \%)$ \\
\hline $\mathrm{MN}$ of the upper-inner quadrant of the breast (C50.20) & $3(9.38 \%)$ \\
\hline $\mathrm{MN}$ of the lower-inner quadrant of the breast (C50.30) & $2(6.25 \%)$ \\
\hline $\mathrm{MN}$ of the upper-outer quadrant of the breast (C50.40) & $13(40.63 \%)$ \\
\hline $\mathrm{MN}$ of the lower-outer quadrant of the breast (C50.50) & $8(25.00 \%)$ \\
\hline $\mathrm{MN}$ of the axillary back of breast (C50.60) & - \\
\hline $\begin{array}{l}\mathrm{MN} \text { (lesion) of breast, which go beyond one or more of } \\
\text { the above localizations (C50.80) }\end{array}$ & $2(6.25 \%)$ \\
\hline $\mathrm{MN}$ breast, unspecified (C50.90) & - \\
\hline Carcinoma in situ of breast, lobular (D05.00) & - \\
\hline Carcinoma in situ of breast, intraductal (D05.10) & - \\
\hline Total & 32 \\
\hline
\end{tabular}

Note: MN - malignant neoplasm.

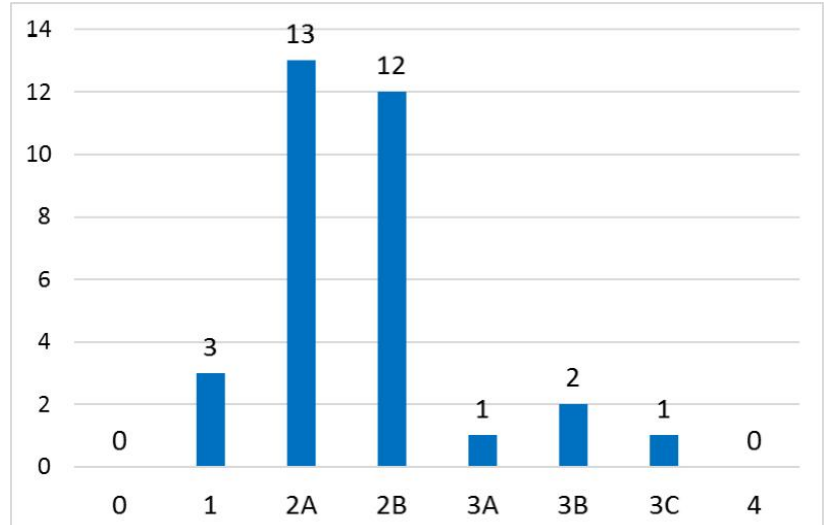

Fig. 1. Stage of the cancer process at the time of diagnosis.

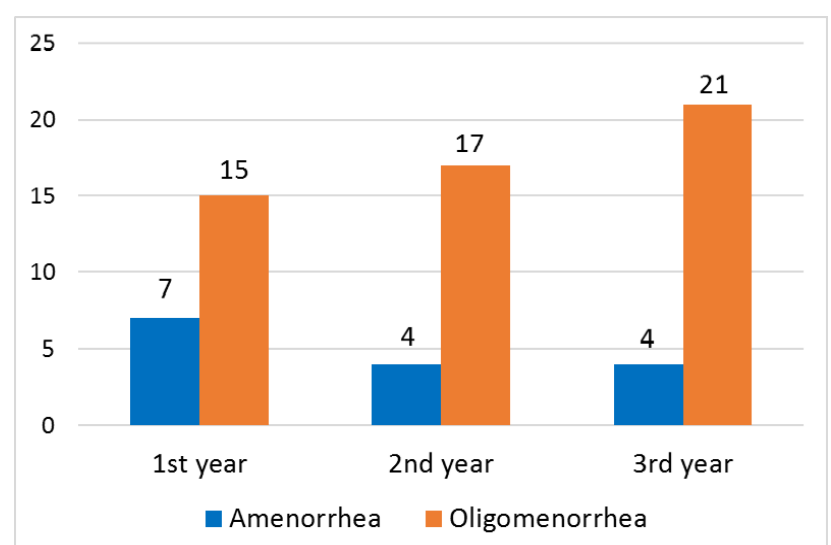

Fig. 2. Frequency of menstrual disorders in the studied contingent. the study sample.

The total number of diagnosed metastases was 47 cases.

Regional metastases accounted for $70.21 \%(n=33)$ of all metastasis cases. The most common localization of regional metastases were axillary lymph nodes, which occurred in $28(84.85 \%)$ cases. In 4 cases metastases to the skin of the breast were diagnosed and in 1 case - to subclavian lymph nodes.

Regarding distant metastasis, their total number was $14(29.79 \%)$ cases. Distant metastases were represented by the following localizations: spine (thoracic and lumbar) - 4; lungs - 3; bones (except for the chest and spine) - 2; mediastinal lymph nodes - 1; pleura - 1; liver - 1; brain - 1; chest skin - 1 .

There was a history of benign breast dysplasia (N60) in 3 patients of the study sample, as well as benign breast cancer (D24.00) in 1 patient. Another 5 patients were diagnosed with a history of erosion or dysplasia of the cervix, glandular hyperplasia of the endometrium and polyp of the uterine body.

Regarding treatment tactics, all patients underwent surgical removal of the tumor. The most common surgeries were radical quadrantectomy (12 patients) and Madden mastectomy (11 patients). Subcutaneous breast amputation was performed in 4 cases, breast hemiresection - in 2 cases, breast amputation, sectoral breast resection and tumor removal - 1 case each. Lymph dissection was performed in 16 patients. Another 3 patients underwent mammoplasty with an endoprosthesis after completion of treatment.

Chemotherapy, as a mandatory component of comprehensive treatment in this sample of patients, was prescribed in a total of 127 courses. In most cases, CAF (Cyclophosphamide + Doxorubicin + 5-Fluorouracil) regimens were prescribed - 55 (43.31\%) courses and AC (Doxorubicin + Cyclophosphamide) courses - 48 $(37.80 \%)$ courses. Other schemes were assigned in the amount of 24 (18.89\%) courses.

Radiation therapy was used in 26 patients. In half of the cases, the irradiation area was the breast, in another 8 
Table 2. Dynamics of changes in the main hormonal parameters of the ovarian reserve.

\begin{tabular}{|c|c|c|c|c|}
\hline \multirow{2}{*}{\multicolumn{2}{|c|}{ Groups }} & \multicolumn{3}{|c|}{ Indicator } \\
\hline & & AMH, ng/ml & $\mathrm{FSH}, \mathrm{mlU} / \mathrm{ml}$ & $\mathrm{E} 2, \mathrm{pg} / \mathrm{ml}$ \\
\hline \multicolumn{2}{|c|}{ Control group $(\mathbf{C})$} & $2.038 \pm 0.822^{* 1,2,3}$ & $6.525 \pm 1.247^{* 1,2,3}$ & $77.44 \pm 11.57^{\star 1,2,3}$ \\
\hline \multirow{4}{*}{ Main group } & Before chemotherapy (BC) & $1.984 \pm 0.781^{* 1,2,3}$ & $6.616 \pm 1.242^{\star 1,2,3}$ & $77.63 \pm 11.56^{\star 1,2,3}$ \\
\hline & 1 year $(1)$ & $0.625 \pm 0.316^{\star c, b c, 2,3}$ & $48.11 \pm 10.38^{\star c, b c, 2,3}$ & $20.18 \pm 3.32^{* \mathrm{c}, \mathrm{bc}, 2,3}$ \\
\hline & 2 year (2) & $0.243 \pm 0.139^{\star c, b c, 1,3}$ & $40.40 \pm 11.73^{\star c, b c, 1}$ & $25.62 \pm 5.42^{* c, b c, 1}$ \\
\hline & 3 year $(3)$ & $0.115 \pm 0.083^{\star c, b c, 1,2}$ & $37.31 \pm 11.80^{* c, b c, 1}$ & $27.29 \pm 7.36^{* c, b c, 1}$ \\
\hline
\end{tabular}

Note. ${ }^{*}$ - significant difference $(p<0.001)$ relative to these groups.

cases - the chest wall. Irradiation of the skin of the axilla, chest wall, intercostal external anterior lymph nodes, brain and spine was performed in one case.

The frequency of menstrual irregularities in patients of the study sample is shown in Figure 2.

Menstrual irregularities were observed in 22 (68.75\%) patients during the first year of the study, in 21 (65.63\%) patients during the second and in $25(78.13 \%)$ patients during the third year of the study.

During the first year, amenorrhea occurred in 7 $(21.88 \%)$ patients. In 3 of them, in the second year of the study, the menstrual cycle was partially restored.

The number of patients with oligomenorrhea progressively increased from $15(46.88 \%)$ in the first year of the study, to $17(53.13 \%)$ in the second year of the study and to $25(78.13 \%)$ in the third year of the study. At the same time, although there was an increase in the number of cases of oligomenorrhea, but such an increase was insignificant $(p>0.05)$.

Of the 32 women, $12(37.50 \%)$ were planning a pregnancy. Spontaneous abortions occurred in $2(6.25 \%)$ patients. $7(21.90 \%)$ patients complained about the impossibility of getting pregnant. Only $3(9.40 \%)$ women ended their pregnancies.

The dynamics of changes in the main hormonal indicators of the ovarian reserve of women in the study sample are shown in table 2.

As can be seen from table 2, the levels of all studied hormones in the main group before chemotherapy did not differ significantly $(p>0.05)$ from the control group, which indicated a satisfactory state of reproductive health of women in the study sample. At the same time, it should be noted that the studied indicators of both the control group and the main group before chemotherapy were within normal values.

Levels of antimullerian hormone in the main group at all terms of the study after chemotherapy were significantly $(p<0.001)$ lower than in the control group, as well as in the main group before chemotherapy. Hormone levels in the study 1 year after chemotherapy were 3.2 times lower than baseline. The studied indicator 2 years after chemotherapy was significantly $(p<0.001)$ lower $(2.59$ times $)$ than the same indicator 1 year earlier. It should also be noted that at year 3 of the study, antimullerian hormone levels were significantly $(p<0.001)$ lower than 1 year $(5.16$ times) and 2 years (2 times) after chemotherapy. In general, antimullerian hormone levels decreased relative to baseline by 3.2 -fold over 1 year, 8.25 -fold during the first two years, and 16.5-fold over the follow-up period.

Changes in estradiol levels were characterized by slightly different dynamics than antimullerian hormone levels.

Estradiol levels in the main group at all terms of the study after chemotherapy were significantly $(p<0.001)$ lower than in the control group, as well as in the main group before chemotherapy. Hormone levels in the study 1 year after chemotherapy were 3.85 times lower than baseline. From the 2nd year of the study, there was a tendency for a slight increase in estradiol levels. The studied indicator 2 years after chemotherapy was significantly $(p<0.001)$ lower (3.03 times) than the initial values, but it significantly $(p<0.001)$ increased relative to the same indicator for 1 year of the study by $26.96 \%$. In addition, at year 3 of the study, estradiol levels were also significantly $(p<0.001)$ lower than after 1 year (2.85 times), and the increase relative to 2 years after chemotherapy was $6.52 \%$. It should also be noted that, although there was a slight increase in the numerical values of estradiol levels during the 3 years of the study, but statistically the differences could not be confirmed ( $p>0.05$ ).

Changes in follicle-stimulating hormone levels were characterized by dynamics opposite to the dynamics of estradiol levels.

Thus, the levels of follicle-stimulating hormone in the main group at all terms of the study after chemotherapy were significantly $(p<0.001)$ higher than the control group, as well as the indicators of the main group before chemotherapy. Hormone levels in the study 1 year after chemotherapy were 7.27 times higher than baseline. From the 2nd year of the study, there was a tendency to a slight decrease in follicle-stimulating hormone levels. The studied indicator 2 years after chemotherapy was significantly $(p<0.001)$ higher $(6.1$ times) than the initial values, but it significantly $(p<0.001)$ decreased relative to the same indicator for 1 year of the study by $16.03 \%$. In addition, at year 3 of the study, follicle-stimulating hormone levels were also significantly $(p<0.001)$ higher than after 1 year (5.63 times), and the decrease relative to 2 years after 
chemotherapy was $7.65 \%$. It should also be noted that, although there was a slight decrease in the numerical values of follicle-stimulating hormone levels during the 3 years of the study, the differences were statistically insignificant ( $p>0.05)$.

As can be seen from table 3 , both ovarian volume and the number of antral follicles in the main group before chemotherapy did not differ significantly $(p>0.05)$ from similar indicators in the control group, which indicated a satisfactory reproductive health of women in the study samples. At the same time, it should be noted that the studied indicators of both the control group and the main group before chemotherapy were within normal values.

The values of ovarian volume in the main group at all terms of the study after chemotherapy were statistically significantly $(p<0.001)$ lower than in the control group, as well as in the main group before chemotherapy. Thus, the values of this indicator in the study after 1 year after chemotherapy were $31.19 \%$, after 2 years - by $37.85 \%$, after 3 years by $41.04 \%$ less than the initial values. The decrease in ovarian volume in the 2 nd year of the study compared to 1 year was $5.08 \%$, in the 3rd year compared to 2 years $-2.30 \%$. In this case, although there was a slight progressive decrease in the numerical values of the studied indicator throughout the study period, but statistically the differences were insignificant ( $p>0.05)$.

The dynamics of changes in the number of antral follicles differed slightly from the dynamics of changes in ovarian volume.

The number of antral follicles in the main group at all stages of the study after chemotherapy was significantly $(p<0.001)$ less than the control group, as well as the indicators of the main group before chemotherapy. The study rate in the study 1 year after chemotherapy was 1.96 times lower than baseline. The studied indicator 2 years after chemotherapy was significantly $(p<0.05)$ lower (by $15.48 \%$ ) than the same indicator 1 year earlier. It should also be noted that at year 3 of the study, antimullerian hormone levels were significantly $(p<0.001)$ lower than at 1 year $(31.46 \%)$ and 2 years $(p<0.05 ; 18.91 \%)$ after chemotherapy. In general, the number of antral follicles decreased relative to baseline values by 1.96 times during 1 year, 2.31 times during the first two years and 2.85 times during the entire observation period.

In the statistical analysis of the correlations between the studied indicators of the ovarian reserve of women in the study sample, the following data were obtained (Table 4).

As can be seen from Table 4 in the studied contingent there were strong correlations between the levels of the studied hormones (antimullerian hormone, folliclestimulating hormone, estradiol). In addition, strong correlations were statistically demonstrated in the analysis of the dependences of the levels of the studied hormones and the number of antral follicles.

At the same time, statistical analysis of the relationship between the levels of hormones studied and ovarian volume
Table 3. Dynamics of changes in the main ultrasound markers of ovarian reserve.

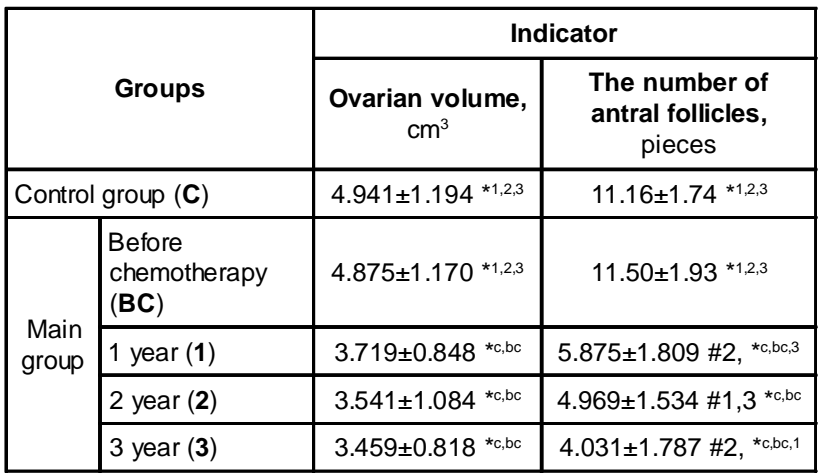

Notes: \# - statistically significant difference $(p<0.05)$ relative to these groups; * - statistically significant difference $(p<0.001)$ relative to these groups.

Table 4. Correlations between the studied indicators of women's ovarian reserve.

\begin{tabular}{|l|c|c|c|}
\hline $\begin{array}{c}\text { The connection under } \\
\text { study }\end{array}$ & $\begin{array}{c}\text { Correlation } \\
\text { coefficient of } \\
\text { Pearson }(\mathbf{r})\end{array}$ & $\begin{array}{c}\text { Probability } \\
\text { (p-level) }\end{array}$ & $\begin{array}{c}95 \% \\
\text { confidence } \\
\text { interval }\end{array}$ \\
\hline Levels of AMH - FSH & -0.71 & $\mathrm{p}<0.001$ & {$[-0.78 ;-0.63]$} \\
\hline Levels of AMH - E2 & 0.71 & $\mathrm{p}<0.001$ & {$[0.62 ; 0.78]$} \\
\hline Levels of FSH - E2 & -0.81 & $\mathrm{p}<0.001$ & {$[-0.86 ;-0.75]$} \\
\hline $\begin{array}{l}\text { Ovarian volume - The } \\
\text { number of AF }\end{array}$ & 0.56 & $\mathrm{p}<0.001$ & {$[0.45 ; 0.66]$} \\
\hline $\begin{array}{l}\text { Levels of AMH - Ovarian } \\
\text { volume }\end{array}$ & 0.48 & $\mathrm{p}<0.001$ & {$[0.35 ; 0.59]$} \\
\hline $\begin{array}{l}\text { Levels of AMH - The } \\
\text { number of AF }\end{array}$ & 0.78 & $\mathrm{p}<0.001$ & {$[0.72 ; 0.84]$} \\
\hline $\begin{array}{l}\text { Levels of FSH - Ovarian } \\
\text { volume }\end{array}$ & -0.44 & $\mathrm{p}<0.001$ & {$[-0.56 ;-0.3]$} \\
\hline $\begin{array}{l}\text { Levels of FSH - The } \\
\text { number of AF }\end{array}$ & -0.73 & $\mathrm{p}<0.001$ & {$[-0.8 ;-0.65]$} \\
\hline $\begin{array}{l}\text { Levels of E2 - Ovarian } \\
\text { volume }\end{array}$ & 0.47 & $\mathrm{p}<0.001$ & {$[0.35 ; 0.59]$} \\
\hline $\begin{array}{l}\text { Levels of E2 - The } \\
\text { number of AF }\end{array}$ & 0.78 & $\mathrm{p}<0.001$ & {$[0.71 ; 0.84]$} \\
\hline
\end{tabular}

Note. AF - antral follicles.

showed a moderate correlation between these indicators. Similarly, a moderate correlation was found in the study of the relationship between ovarian volume and the number of antral follicles.

\section{Discussion}

Chemotherapeutic drugs differ significantly in the mechanisms of cytotoxic effects on living cells. These mechanisms correlate with the risk of premature chemoinduced ovarian failure and infertility.

Thus, the active metabolites of alkylating antineoplastic drugs (Cyclophosphamide, Mechloretamine, Chlorambucil) are attached to the DNA of the target cell, which is accompanied by inhibition of DNA synthesis and function. This leads to rupture of DNA chains and, as a consequence, to P63-mediated apoptosis in primordial 
follicles $[3,34,37,38]$. The use of these drugs is accompanied by a high risk of infertility [3].

Platinum preparations (Cisplatin, Carboplatin) covalently bind to DNA, forming intra-chain DNA cross-links. This leads to DNA rupture during replication, inhibition of transcription, disruption of synthesis and DNA function [3, $25,31]$. The use of platinum drugs is accompanied by a moderate risk of infertility [3].

The mechanism of action of drugs of the group of antimetabolites (5-Fluorouracil, Methotrexate) is to inhibit the synthesis of DNA, RNA, thymidylate and purine $[3,22$, 28]. Drugs of this group have virtually no gonadotoxic effects and are characterized by a low risk of infertility [3].

Vinca alkaloids (Vincristine, Vinblastine) are antitumor agents of plant origin. The mechanism of their action is to inhibit the polymerization of tubulin and disruption of the assembly of microtubules during mitosis $[3,8,26]$. The risk of infertility with this group of drugs is low [3].

Drugs of the group of anthracycline antibiotics (Doxorubicin, Bleomycin, Mitomycin) inhibit the synthesis and function of DNA, disrupt the transcription process [3, 4, $25,43]$. Inhibition of topoisomerase II leads to DNA breaks. In addition, drugs of this group are involved in the formation of toxic oxygen-free radicals that cause breaks in DNA chains, thereby inhibiting the synthesis and functioning of DNA. Doxorubicin induces double-stranded DNA breaks and P63-mediated apoptosis in primordial follicles. Drugs of this group have virtually no gonadotoxic effects and are accompanied by a low risk of infertility with the exception of Doxorubicin, the risk of infertility in the use of which is characterized as moderate [3].

In our study, in the vast majority of cases, chemotherapy regimens with Cyclophosphamide and Doxorubicin were prescribed, which are accompanied by, respectively, a high and moderate risk of premature chemoinduced ovarian failure and infertility [3, 34, 37, 38].

The study of the clinical and anamnestic component of the reproductive health of women in the studied contingent showed trends similar to those described in the scientific medical literature [5, 41]. Quite significant changes in women's reproductive health manifested themselves in the form of menstrual disorders (oligomenorrhea, amenorrhea), involuntary abortions, inability to conceive.

The progressive decrease in antimullerian hormone levels throughout the study period can be explained on the one hand by ovariotoxic and general toxic effects of chemotherapeutic agents [2], and on the other - by agerelated decrease in ovarian reserve $[9,35]$. At the same time, the decrease in the studied indicator during 1 year of the study is mainly due to the ovariotoxic effect of cytostatics. Further slight decrease in hormone levels can be explained both by the progression of dystrophic changes after chemotherapy and by age-related changes in women.

The mutually opposite dynamics of changes in estradiol and follicle-stimulating hormone levels is explained as follows. The decrease in estradiol levels during 1 year of the study is explained by ovariotoxic and general toxic effects of chemotherapeutic agents [29]. At the same time, the decrease in estradiol levels caused an increase in follicle-stimulating hormone levels through a feedback mechanism [13]. Cessation of the toxic effects of chemotherapeutic drugs and partial tissue regeneration allowed to slightly restore estradiol levels and, accordingly, to slightly reduce follicle-stimulating hormone levels.

Despite the fact that both antimullerian hormone and estradiol are produced by follicles, there has been varying degrees of reduction in their levels. In our opinion, this can be explained by the fact that antimullerian hormone is produced exclusively by follicles, while estradiol, in addition to follicles, is additionally produced by the adrenal cortex and adipose tissue [13].

In our opinion, the decrease in the values of both ovarian volume and the number of antral follicles during the study period can be explained as follows. A sharp decrease in the studied indicators during 1 year of the study is probably due mainly to the ovariotoxic effects of chemotherapeutic agents [3]. Further slight decrease in ovarian volume and number of antral follicles can be explained, on the one hand, by the progression of dystrophic changes after chemotherapy [3], and on the other - by age-related involution of the ovaries of women in the study sample [13].

In our opinion, the strong correlations between the levels of hormones studied and the number of antral follicles can be explained by the fact that antimullerian hormone and estradiol are directly produced by ovarian follicles, and the level of follicle-stimulating hormone depends on estradiol levels.

Ovariotoxic effects of chemotherapy can be manifested as a direct effect on the follicular apparatus of the ovaries, and indirectly through the vascular component on other ovarian tissues. Reducing the number of vessels of the microcirculatory tract of the ovaries, in turn, leads to a decrease in trophism of all tissues, including ovarian follicles [4, 12]. In our analysis, this double toxic effect on the ovarian follicle is confirmed by a faster rate of antral follicle reduction compared to ovarian volume, on the one hand, and a moderate correlation between these parameters.

\section{Conclusion}

1. In the contingent of women suffering from malignant neoplasms of the breast, the share of women of reproductive age is $24.70 \%$, and chemotherapy, as part of comprehensive treatment, receive $19.90 \%$ of women.

2. The frequency of menstrual disorders during the first year after chemotherapy is $68.75 \%$, and after 2 years increases to $78.13 \%$.

3. The dynamics of changes in the main hormonal and ultrasound parameters of the ovarian reserve indicates a significant violation of reproductive function in women who received chemotherapy for malignant neoplasms of the breast. 


\section{References}

[1] Abdulrahman, G. O., Jr., \& Rahman, G. A. (2012). Epidemiology of breast cancer in europe and Africa. Journal of cancer epidemiology, 2012, 915610. doi: 10.1155/2012/915610

[2] Anderson, R. A., \& Su, H. I. (2020). The Clinical Value and Interpretation of Anti-Müllerian Hormone in Women With Cancer. Frontiers in endocrinology, 11, 574263. doi: 10.3389/ fendo.2020.574263

[3] Bedoschi, G., Navarro, P. A., \& Oktay, K. (2016). Chemotherapyinduced damage to ovary: mechanisms and clinical impact. Future oncology (London, England), 12(20), 2333-2344. doi: 10.2217/fon-2016-0176

[4] Ben-Aharon, I., Bar-Joseph, H., Tzarfaty, G., Kuchinsky, L., Rizel, S., Stemmer, S. M., \& Shalgi, R. (2010). Doxorubicininduced ovarian toxicity. Reproductive biology and endocrinology: RB\&E, 8, 20. doi: 10.1186/1477-7827-8-20

[5] Busnelli, A., Vitagliano, A., Mensi, L., Acerboni, S., Bulfoni, A., Filippi, F., \& Somigliana, E. (2020). Fertility in female cancer survivors: a systematic review and meta-analysis. Reproductive biomedicine online, 41(1), 96-112. doi: 10.1016/ j.rbmo.2020.02.008

[6] Cardoso, F., Colleoni, M., Leo, A. D., Francia, D., Gennari, A., Gligorov, J., \& Llombart, A. (2016). Oral chemotherapy in advanced breast cancer: expert perspectives on its role in clinical practice. Cancer Treatment Communications, 6(1), 1-10. doi: 10.1016/S2213-0896(16)06001-1

[7] Carioli, G., Malvezzi, M., Rodriguez, T., Bertuccio, P., Negri, E., \& La Vecchia, C. (2018). Trends and predictions to 2020 in breast cancer mortality: Americas and Australasia. Breast (Edinburgh, Scotland), 37, 163-169. doi: 10.1016/ j.breast.2017.12.004

[8] Chagas, C. M., \& Alisaraie, L. (2019). Metabolites of Vinca Alkaloid Vinblastine: Tubulin Binding and Activation of NauseaAssociated Receptors. ACS omega, 4(6), 9784-9799. doi: 10.1021/acsomega.9b00652

[9] Cui, L., Qin, Y., Gao, X., Lu, J., Geng, L., Ding, L., ... \& Chen, Z. J. (2016). Antimüllerian hormone: correlation with age and androgenic and metabolic factors in women from birth to postmenopause. Fertility and sterility, 105(2), 481-485. doi: 10.1016/j.fertnstert.2015.10.017

[10] DeSantis, C. E., Ma, J., Goding Sauer, A., Newman, L. A., \& Jemal, A. (2017). Breast cancer statistics, 2017, racial disparity in mortality by state. CA: a cancer journal for clinicians, $67(6)$, 439-448. doi: 10.3322/caac. 21412

[11] Ejlertsen B. (2016). Adjuvant chemotherapy in early breast cancer. Danish medical journal, 63(5), B5222. PMID: 27127018

[12] Farokhi, F., Sadrkhanlou, R., Hasanzadeh, S. H., Sultanalinejad, F. (2007). Morphological and morphometrical study of cyclophosphamide-induced changes in the ovary and uterus in the Syrian mice. Iranian Journal of Veterinary Research, 8(4), 337-342. doi: 10.22099/ijvr.2007.11

[13] Feher, J. (2012). Quantitative Human Physiology: An Introduction (2nd ed.). Elsevier Inc.: Academic Press. doi: 10.1016/B978-0-12-382163-8.00092-X

[14] Ferley, J., Soerjomatarami, I., Ervik, M., Dikshit, R., Eser, S. (2013). GLOBOCAN 2012 v1.0. Cancer Incidence and Mortality Worldwide: IARC Cancer Base No. 11. Lyon, France: International Agency for Research on Cancer.

[15] Ghoncheh, M., Mohammadian-Hafshejani, A., \& Salehiniya, H. (2015). Incidence and Mortality of Breast Cancer and their Relationship to Development in Asia. Asian Pacific journal of cancer prevention : APJCP, 16(14), 6081-6087. doi: 10.7314/ apjcp.2015.16.14.6081

[16] Ghoncheh, M., Momenimovahed, Z., \& Salehiniya, H. (2016). Epidemiology, Incidence and Mortality of Breast Cancer in Asia. Asian Pacific journal of cancer prevention : APJCP, 17(S3), 47-52. doi: 10.7314/apjcp.2016.17.s3.47

[17] Ghoncheh, M., Pournamdar, Z., \& Salehiniya, H. (2016). Incidence and Mortality and Epidemiology of Breast Cancer in the World. Asian Pacific journal of cancer prevention : APJCP, 17(S3), 43-46. doi: 10.7314/apjcp.2016.17.s3.43

[18] Goldhirsch, A., Winer, E. P., Coates, A. S., Gelber, R. D., PiccartGebhart, M., Thürlimann, B., ... \& Panel members (2013). Personalizing the treatment of women with early breast cancer: highlights of the St Gallen International Expert Consensus on the Primary Therapy of Early Breast Cancer 2013. Annals of oncology : official journal of the European Society for Medical Oncology, 24(9), 2206-2223. doi: 10.1093/annonc/mdt303

[19] Gomez, S. L., Von Behren, J., McKinley, M., Clarke, C. A., Shariff-Marco, S., Cheng, I., ... \& Glaser, S. L. (2017). Breast cancer in Asian Americans in California, 1988-2013: increasing incidence trends and recent data on breast cancer subtypes. Breast cancer research and treatment, 164(1), 139-147. doi: 10.1007/s10549-017-4229-1

[20] Hortobagyi, G. N., de la Garza Salazar, J., Pritchard, K., Amadori, D., Haidinger, R., Hudis, C. A., ... \& ABREAST Investigators (2005). The global breast cancer burden: variations in epidemiology and survival. Clinical breast cancer, 6(5), 391401. doi: $10.3816 /$ cbc.2005.n.043

[21] Kim, Y., Yoo, K. Y., \& Goodman, M. T. (2015). Differences in incidence, mortality and survival of breast cancer by regions and countries in Asia and contributing factors. Asian Pacific journal of cancer prevention : APJCP, 16(7), 2857-2870. doi: 10.7314/apjcp.2015.16.7.2857

[22] Koźmiński, P., Halik, P. K., Chesori, R., \& Gniazdowska, E. (2020). Overview of Dual-Acting Drug Methotrexate in Different Neurological Diseases, Autoimmune Pathologies and Cancers. International journal of molecular sciences, 21(10), 3483. doi: 10.3390/ijms21103483

[23] Meirow, D., Dor, J., Kaufman, B., Shrim, A., Rabinovici, J., Schiff, E., ... \& Fridman, E. (2007). Cortical fibrosis and bloodvessels damage in human ovaries exposed to chemotherapy. Potential mechanisms of ovarian injury. Human reproduction (Oxford, England), 22(6), 1626-1633. doi: 10.1093/humrep/ dem027

[24] Momenimovahed, Z., \& Salehiniya, H. (2019). Epidemiological characteristics of and risk factors for breast cancer in the world. Breast cancer (Dove Medical Press), 11, 151-164. doi: 10.2147/BCTT.S176070

[25] Morgan, S., Lopes, F., Gourley, C., Anderson, R. A., \& Spears, N. (2013). Cisplatin and doxorubicin induce distinct mechanisms of ovarian follicle loss; imatinib provides selective protection only against cisplatin. PloS one, 8(7), e70117. doi: 10.1371/journal.pone.0070117

[26] Moudi, M., Go, R., Yien, C. Y., \& Nazre, M. (2013). Vinca alkaloids. International journal of preventive medicine, 4(11), 1231-1235. PMID: 24404355

[27] Overbeek, A., van den Berg, M. H., van Leeuwen, F. E., Kaspers, G. J., Lambalk, C. B., \& van Dulmen-den Broeder, E. (2017). Chemotherapy-related late adverse effects on ovarian function in female survivors of childhood and young adult cancer: A systematic review. Cancer treatment reviews, 53, 10-24. doi: 10.1016/j.ctrv.2016.11.006 
[28] Papanastasopoulos, P., \& Stebbing, J. (2014). Molecular basis of 5-fluorouracil-related toxicity: lessons from clinical practice. Anticancer research, 34(4), 1531-1535. PMID: 24692679

[29] Pribylova, O., Springer, D., Svobodnik, A., Kyr, M., Zima, T., \& Petruzelka, L. (2008). Influence of chemotherapy to hormonal levels in postmenopausal breast cancer patients. Neoplasma, 55(4), 294-298. PMID: 18505339

[30] Prieto-Callejero, B., Rivera, F., Fagundo-Rivera, J., Romero, A., Romero-Martín, M., Gómez-Salgado, J., \& Ruiz-Frutos, C. (2020). Relationship between chemotherapy-induced adverse reactions and health-related quality of life in patients with breast cancer. Medicine, 99(33), e21695. doi: 10.1097/ MD.0000000000021695

[31] Riddell, I. A. (2018). Cisplatin and Oxaliplatin: Our Current Understanding of Their Actions. Metal ions in life sciences, 18, /books/9783110470734/9783110470734-007/ 9783110470734-007.xml. doi: 10.1515/9783110470734-007

[32] Riedel, F., Hoffmann, A. S., Moderow, M., Heublein, S., Deutsch, T. M., Golatta, M., ... \& Hennigs, A. (2020). Time trends of neoadjuvant chemotherapy for early breast cancer. International journal of cancer, 147(11), 3049-3058. doi: 10.1002/ijc.33122

[33] Rojas, K., \& Stuckey, A. (2016). Breast Cancer Epidemiology and Risk Factors. Clinical obstetrics and gynecology, 59(4), 651-672. doi: 10.1097/GRF.0000000000000239

[34] Saoji, V. A. (2008). Premature ovarian failure due to cyclophosphamide: a report of four cases in dermatology practice. Indian journal of dermatology, venereology and leprology, 74(2), 128-132. doi: 10.4103/0378-6323.39696

[35] Scheffer, J., Scheffer, B., Scheffer, R., Florencio, F., Grynberg, M., \& Lozano, D. M. (2018). Are age and anti-Müllerian hormone good predictors of ovarian reserve and response in women undergoing IVF?. JBRA assisted reproduction, 22(3), 215220. doi: 10.5935/1518-0557.20180043

[36] Schirrmacher, V. (2019). From chemotherapy to biological therapy: A review of novel concepts to reduce the side effects of systemic cancer treatment (Review). International journal of oncology, 54(2), 407-419. doi: 10.3892/ijo.2018.4661
[37] Soleimani, R., Heytens, E., Darzynkiewicz, Z., \& Oktay, K. (2011). Mechanisms of chemotherapy-induced human ovarian aging: double strand DNA breaks and microvascular compromise. Aging, 3(8), 782-793. doi: 10.18632/aging.100363

[38] Spears, N., Lopes, F., Stefansdottir, A., Rossi, V., De Felici, M., Anderson, R. A., \& Klinger, F. G. (2019). Ovarian damage from chemotherapy and current approaches to its protection. Human reproduction update, 25(6), 673-693. doi: 10.1093/ humupd/dmz027

[39] Torino, F., Barnabei, A., De Vecchis, L., Sini, V., Schittulli, F., Marchetti, P., \& Corsello, S. M. (2014). Chemotherapy-induced ovarian toxicity in patients affected by endocrine-responsive early breast cancer. Critical reviews in oncology/hematology, 89(1), 27-42. doi: 10.1016/j.critrevonc.2013.07.007

[40] Torre, L. A., Bray, F., Siegel, R. L., Ferlay, J., Lortet-Tieulent, J., \& Jemal, A. (2015). Global cancer statistics, 2012. CA: a cancer journal for clinicians, 65(2), 87-108. doi: 10.3322/caac.21262

[41] Waimey, K. E., Smith, B. M., Confino, R., Jeruss, J. S., \& Pavone, M. E. (2015). Understanding Fertility in Young Female Cancer Patients. Journal of women's health (2002), 24(10), 812-818. doi: 10.1089/jwh.2015.5194

[42] Williams, L. J., Fletcher, E., Douglas, A., Anderson, E., McCallum, A., Simpson, C. R., ... \& Wild, S. H. (2018). Retrospective cohort study of breast cancer incidence, health service use and outcomes in Europe: a study of feasibility. European journal of public health, 28(2), 327-332. doi: 10.1093/eurpub/ ckx127

[43] Xiao, S., Zhang, J., Liu, M., Iwahata, H., Rogers, H. B., \& Woodruff, T. K. (2017). Doxorubicin Has Dose-Dependent Toxicity on Mouse Ovarian Follicle Development, Hormone Secretion, and Oocyte Maturation. Toxicological sciences : an official journal of the Society of Toxicology, 157(2), 320329. doi: $10.1093 /$ toxsci/kfx047

[44] Youlden, D. R., Cramb, S. M., Yip, C. H., \& Baade, P. D. (2014). Incidence and mortality of female breast cancer in the AsiaPacific region. Cancer biology \& medicine, 11(2), 101-115. doi: 10.7497/j.issn.2095-3941.2014.02.005 